\title{
Quantification of microstructural changes during first stage air drying of grape tissue
}

\author{
Inês N. Ramos ${ }^{\text {a }}$, Cristina L.M. Silva ${ }^{\mathrm{a}, *}$, Alberto M. Sereno ${ }^{\mathrm{b}}$, José M. Aguilera ${ }^{\mathrm{c}}$ \\ ${ }^{a}$ Escola Superior de Biotecnologia, Universidade Católica Portuguesa, Rua Dr. António Bernardino de Almeida, \\ 4200-072 Porto, Portugal \\ ${ }^{\mathrm{b}}$ CEQUP/Departamento de Engenharia Química, Faculdade de Engenharia, Universidade do Porto, \\ Rua Dr. Roberto Frias, s/n 4200-465 Porto, Portugal \\ ${ }^{\mathrm{c}}$ Departamento de Ingenieria Quimica y Bioprocesos, Escuela de Ingenieria, Pontificia Universidad Católica de Chile, \\ Av. Vicuña Mackenna 4860, Macul, C.P. 6904411 Santiago, Chile
}

Keywords: Microstructure; Shrinkage; Kinetics; Modelling; Drying; Grapes; Stereo-microscopy

\begin{abstract}
Microstructural changes in cells of Ruby grape (Vitis vinifera) quarters were monitored during first stage of convective air drying, under a stereo-microscope. A gradual overall shrinkage of grape cells was observed during the process. The cellular parameters: area, perimeter, major and minor axis length, Feret diameter, elongation, roundness and compactness, were quantified by image analysis. It was verified that cell dimensions suffered modifications during drying, but their shape remained unchanged. These microstructural changes showed a smooth exponential decrease with time, and a first-order kinetic model was satisfactorily fitted to the data. Temperature increased the rate of cellular shrinkage and this effect followed an Arrhenius type behaviour. Increasing temperature from 20 to $60{ }^{\circ} \mathrm{C}$ resulted in a $350 \%$ increase of the area change rate. For the parameters related to cellular dimensions, the magnitude of the values were $10^{-3} \mathrm{~min}^{-1}$ for the rate of change at $40{ }^{\circ} \mathrm{C}$ and $3 \mathrm{~kJ} / \mathrm{mol}$ for the activation energy.
\end{abstract}

\section{Introduction}

Drying is probably the oldest method for preserving fruits and initially was used as a way of storing foods for the low season. With the development of new preservation methods and easiness to obtain fresh fruits in the market, drying is currently regarded as one more method for diversifying products for consumer's convenience. Although it has lost its importance facing newer technologies, sun drying in particular is widely used in developing countries. One of the major sun drying products are raisins (Ratti \& Mujumdar, 1996). The most common grape (Vitis vinifera) varieties used for making raisins are Thompson Seedless, Black Corinth and Muscat of Alexandria (Patil, Chakrawar, Narwadkar, \& Shinde, 1995). Raisins are usually in-

\footnotetext{
* Corresponding author. Tel.: +351-22-5580058; fax: +351-225090351.

E-mail addresses: crislui@esb.ucp.pt (C.L.M. Silva), sereno@) fe.up.pt (A.M. Sereno), jmaguile@ing.puc.cl (J.M. Aguilera).
}

cluded in breakfast cereals, dairy, bakery and confectionery products, and more recently in nutritional bars.

Air drying leads to major changes in the fruit structure and texture, such as fruit 'softening' or loss of firmness (Bolin \& Huxsoll, 1987). Texture of dried fruits is very important when they are consumed after rehydration in breakfast cereals, dairy and bakery products. Drying conditions play an active role in determining the textural properties of dried fruits. Slow drying, achieved by low temperature, low air velocity and high air relative humidity, leads to uniform and dense products (Brennan, 1994) with reduced re-hydration rate and capacity (Karathanos, Kanellopoulos, \& Belessiotis, 1996). On the other hand, fast drying rates result in less dense but tougher products, with a crust on the surface (Potter \& Hotchkiss, 1998), and with higher rehydration rate and rehydrated products with soft texture (Brennan, 1994).

Physical properties of foods, and texture in particular, may be related to their microstructure (Aguilera \& Stanley, 1999). The initial work of Reeve (1943) and Crafts (1944) reported the effect of drying on fruit and 


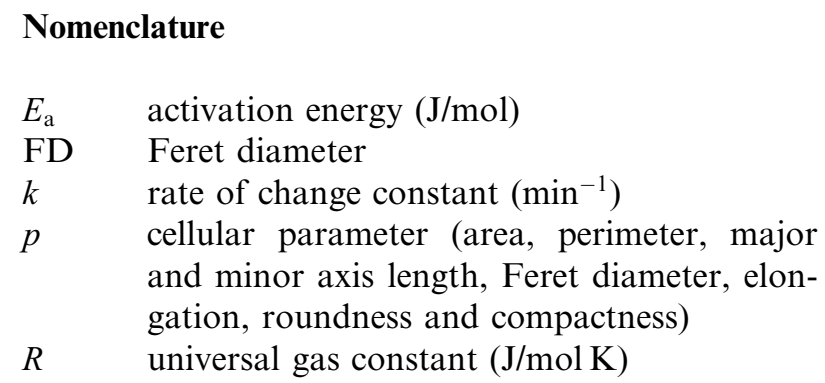

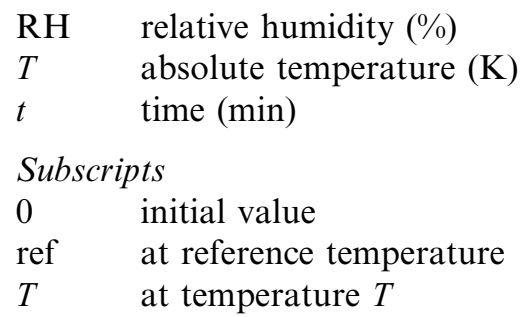

vegetable microstructure, and considered shrinkage of tissues as a major physical change. Long neglected in the formulation of drying models, shrinkage is recognised now as an important consequence of fruit drying that has to be accounted for, since it modifies the shape and dimension of products (Wang \& Brennan, 1995), which in turn affects the mass transport phenomena. Cellular shrinkage causes modifications in the global structure of fruits and is directly related to the loss of water during drying. According to Hills and Remigereau (1997), who studied the air-drying of parenchyma apple tissue, drying results in loss of water from the vacuolar compartment, with minor changes in the water content of either the cytoplasm or the cell wall compartments. Water loss during drying causes loss of turgor pressure, which depends on the osmotic pressure and induces plasmolysis (Jewell, 1979), affecting cellular wall integrity. In cellular tissues it is the turgor pressure that keeps them firm, thus it is related to fruit texture.

Shrinkage of fruits also results in 'case hardening', a phenomenon that occurs in some drying processes. This phenomenon is more frequently observed when the drying rate is fast. As the fruit surface dries much faster than its core, internal stresses develop and the fruit interior becomes cracked and porous (Aguilera \& Stanley, 1999). Non-volatile compounds migrate with the diffusing water, precipitate on the product's surface and form a crust that keeps the fruit dimensions thereafter. Consequently, at higher drying velocities the overall degree of fruit shrinkage is smaller. Wang and Brennan (1995) observed this phenomenon by microscopy during potato drying experiments.

Changes in geometric features of cells may be quantified by image analysis (Bolin \& Huxsoll, 1987). Nowadays, several microscopes with high magnification and resolution power, can be used to study food microstructure (e.g. scanning electron microscopy is widely used). Microscopy is a powerful non-invasive tool for studying food microstructure, especially if complemented with techniques of image analysis (Jewell, 1979). Stereo-microscopy has limited magnification, but due to its large focal distance it allows the observation of large fruit pieces during drying, unlike other methods in which it is only possible to visualise a small region of a transparent sample. Preparative techniques are fast and do not originate many alterations of the sample. The information obtained from the microscope is then suitable for quantification, using software for image analysis (Aguilera \& Lillford, 1997).

The main goal of this research was to introduce a microstructural approach in drying of fruits. Observing what happens at the microscopic level during drying will result not only on qualitative information, but also on quantitative data suitable for modelling. Therefore, a more specific objective was to quantify physical microstructural changes during air drying of grapes quarters, and in particular to quantify cellular shrinkage.

\section{Material and methods}

\section{Samples}

Fresh grapes (Vitis vinifera) from the Ruby variety, were bought from a local market and stored in a refrigerator for two weeks. Water content was determined using a vacuum oven at $70{ }^{\circ} \mathrm{C}$, until a stable weight value was reached. Original grapes had a mean water content of $80.6 \% \pm 0.1(\mathrm{w} / \mathrm{w})$ on wet basis. Grape quarters of approximately $2.4 \mathrm{~cm}$ diameter were cut with a razor blade, as it is schematically presented in Fig. 1a. Cellular walls were stained in a solution of methylene blue $0.034 \%$, during $15 \mathrm{~s}$ prior to drying.

\section{Drying experiments}

Experiments were carried out using a drying stage mounted under a stereo-microscope (Olympus SZ11, Tokyo, Japan) (Fig. 1b). Two electrical resistances and a fan were mounted inside a $10 \mathrm{~cm}$-diameter stainless steel tube and thermally insulated with glass wool, creating a forced hot airflow. Temperature was monitored with a digital thermometer (Delta Ohm HD8802, Padova, Italy) and a thermocouple (type K). Air relative humidity and velocity were measured with a hygrometer 


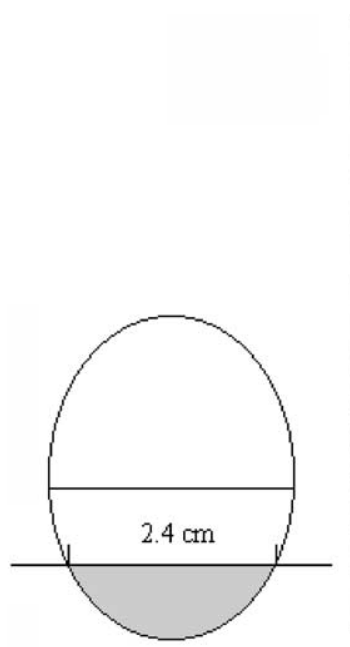

(a)

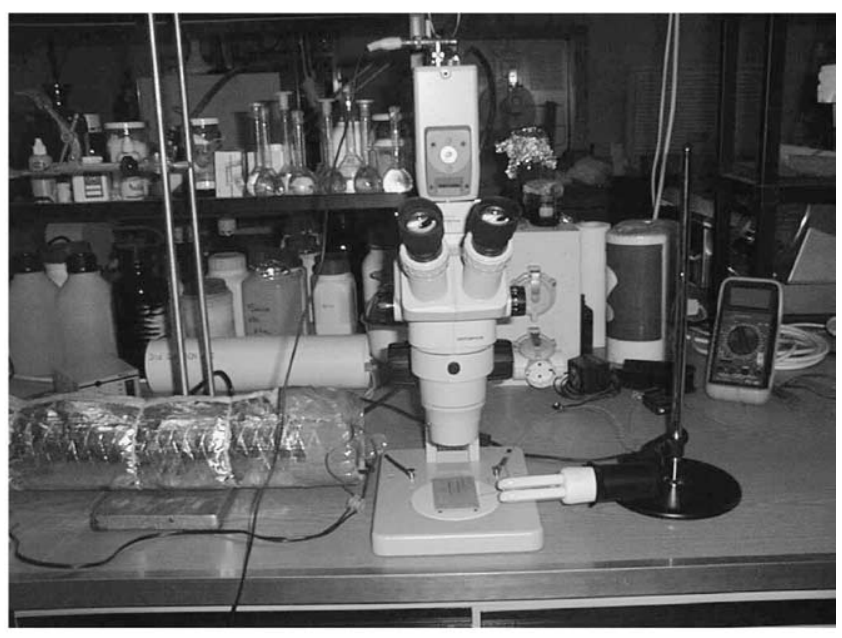

(b)

Fig. 1. (a) Schematic draw to cut the sample. Shadowed part was used for drying. (b) Stereo-microscope with video camera and air-drying tube.

(Rotronic AM3, New York, USA) and an anemometer (Airflow LCA 6000, Buckinghamshire, England), respectively.

A grape quarter was held on the top of four pins attached into a support, and placed under the microscope objective. Drying experiments were carried out in duplicate at $20{ }^{\circ} \mathrm{C}(49.2 \%$ mean air relative humidity, $\mathrm{RH}), 30{ }^{\circ} \mathrm{C}(36.1 \% \mathrm{RH}), 40{ }^{\circ} \mathrm{C}(12.5 \% \mathrm{RH}), 50{ }^{\circ} \mathrm{C}$ $(10.4 \% \mathrm{RH})$ and $60{ }^{\circ} \mathrm{C}(2.2 \% \mathrm{RH})$, with a constant air velocity of $1.6 \pm 0.1 \mathrm{~m} / \mathrm{s}$. Experiments took between $2 \mathrm{~h}$ for the higher temperatures and $4 \mathrm{~h}$ for lower temperatures.

\section{Microstructure and image analysis}

A group of cells was continuously focused with the stereo-microscope during drying, under a magnification of $25 \times$. A digital colour video-camera (Sony Exwave Had, Tokyo, Japan) was attached to the microscope and then connected to a TV monitor and a personal computer. Image acquisition was done with an interface (Logitech Snappy, Rancho Cordova, USA) and images were captured at given time intervals with Snappy software. This technique allows monitoring the same group of cells during the first stage of drying. For each experiment, a group of 20 cells was selected for further amplification and analysis with Paint Shop Pro 4.12 and UTHSCSA Image Tool 2.0 (University of Texas Health Science Center, Texas, USA) software. Each cell was delimited and several geometrical parameters were determined using the specified software: area, perimeter, major and minor axis length, Feret diameter, elongation, roundness and compactness. Parameters such as Feret diameter (FD), elongation, roundness and compactness were defined as follows:

$$
\begin{aligned}
& \mathrm{FD}=2 \sqrt{\frac{\text { area }}{\pi}} \\
& \text { elongation }=\frac{\text { major axis length }}{\text { minor axis length }} \\
& \text { roundness }=\frac{4 \pi \text { area }^{\text {perimeter }^{2}}}{\text { compactness }=\frac{\mathrm{FD}}{\text { major axis }}}
\end{aligned}
$$

Elongation, roundness and compactness are indicators of the circularity of the cell. Cells with shape closer to a perfect circle present values of elongation, roundness and compactness closer to one.

At selected times, during each experiment, each geometric cellular parameter was evaluated for all the selected 20 cells and a mean value was calculated.

\section{Data analysis}

In order to eliminate initial variability between different berries and even different cell groups, every cellular parameter was normalised (i.e. divided by its initial value, at zero time). Experimental data for each cellular parameter related to dimension, were mathematically modelled. The effect of drying time, at constant temperature, was described by a first order kinetics:

$\frac{p}{p_{0}}=\exp \left(-k_{T} t\right)$

where $p$ is the cellular parameter value; $p_{0}$ its initial value at time zero; $t$, the time and $k_{T}$ is the rate of change constant at a given temperature $(T)$.

Arrhenius law was used to model the temperature effect on the rate of change constant: 
$k=k_{\text {ref }} \exp \left[-\frac{E_{\mathrm{a}}}{R}\left(\frac{1}{T}-\frac{1}{T_{\text {ref }}}\right)\right]$

where $k_{\text {ref }}$ is the rate of change constant at a reference temperature, $T_{\text {ref }}, E_{\text {a }}$ the activation energy, $R$ the universal gas constant and $T$ the absolute temperature.

A one-step non-linear regression was simultaneously performed to all data (Arabshahi \& Lund, 1985; Lund, 1983) using the statistical software STATA version 3.0 (Texas, USA). For every cellular parameter related to dimension, a rate of change constant at reference temperature $\left(40{ }^{\circ} \mathrm{C}\right)$, an activation energy and the corresponding $95 \%$ confidence intervals were obtained.

For cellular parameters related with shape a two-way analysis of variance was performed for unbalanced data at a $95 \%$ confidence level.

\section{Results and discussion}

As expected, a gradual overall shrinkage of the grape cells was observed with drying time (Fig. 2). Disruption of cellular walls with consequent cellular collapse, was clear in some experiments. At the beginning of drying the surface became brilliant due to the gradual increase of liquid water.

Results obtained from image analysis presented two distinct behaviours. Cellular parameters directly related to dimensions (area, perimeter, major and minor axis length and Feret diameter) clearly decreased with drying time. Fig. 3 presents the results at $40{ }^{\circ} \mathrm{C}$, and similar results were obtained at $20,30,50$ and $60{ }^{\circ} \mathrm{C}$. The remaining parameters (elongation, roundness and compactness), related to the cells shape, presented normalised values randomly distributed around one (Fig. 4), thus no significant changes were noticed. Experiments were concluded much before the drying equilibrium had been reached. For long drying times, visualisation of cellular walls became difficult, because they begin to collapse due to the material characteristics and the drying process itself. This phenomenon, also

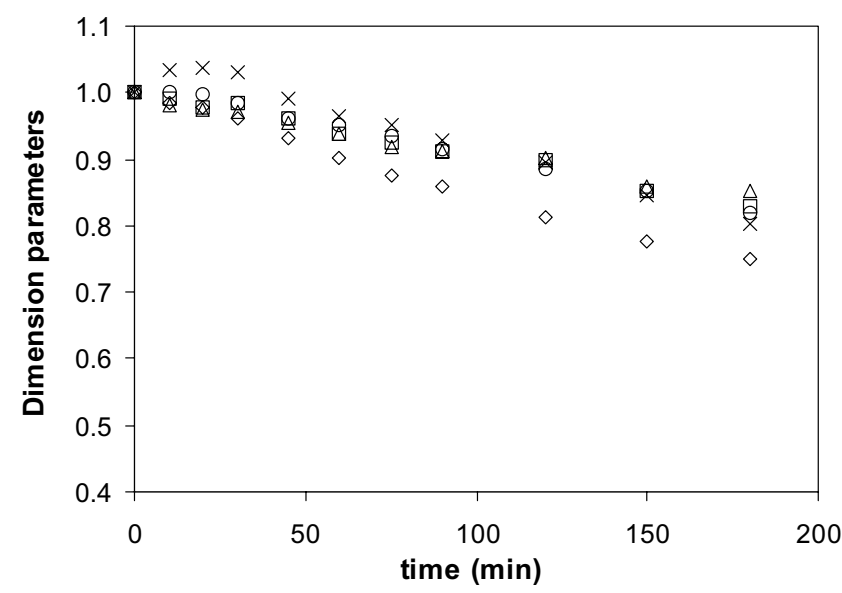

Fig. 3. Experimental dimension cellular parameters, at $40{ }^{\circ} \mathrm{C}$, as a function of time. $(\diamond)$ area, $(\square)$ perimeter, $(\triangle)$ major axis length, $(X)$ minor axis length, (O) Feret diameter.

reported by Reeve (1943), is accelerated at higher temperatures.

Cellular area was found to be the most interesting parameter to study, because it is directly related to shrinkage. In the studied first stage of drying, cellular area as a function of time showed a smooth exponential decrease, being evident for the higher temperatures, when drying is closer to equilibrium. In a drying process, the removal of water proceeds till foods reach an equilibrium water content (Foust, Wenzel, Clump, Maus, \& Andersen, 1980), and in a similar way, the same should happen for fruits macro and cellular dimensions. Theoretically, dimensional parameters should reach an equilibrium value different from zero, if drying had finished. According to this, data was well described by a first-order model (Eq. (5)), with higher temperatures leading to an acceleration of the rate of area decrease (Fig. 5). Experimental values, model predicted values and corresponding residuals, obtained from one-step non-linear regression, may be observed in Fig. 5. Thus, higher temperatures led to an increase in cellular shrinkage of grape quarters. As an example, a change in
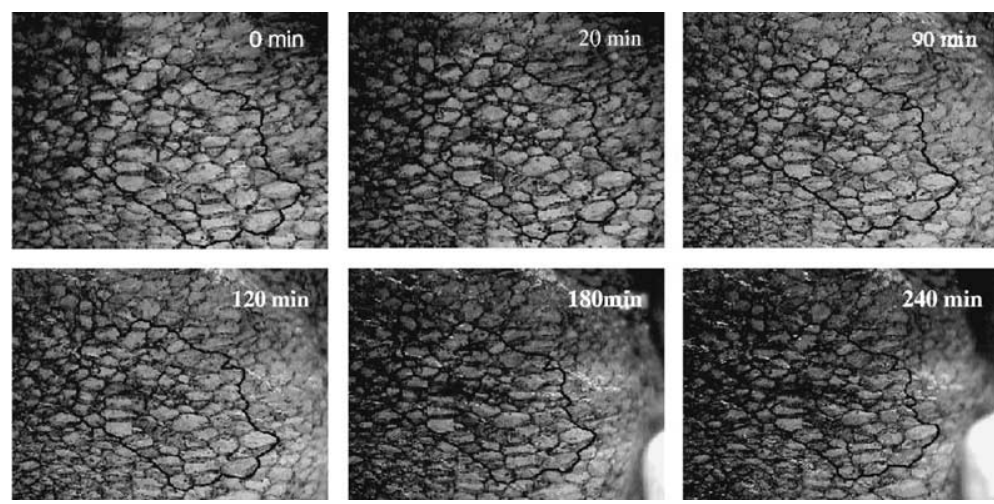

Fig. 2. Images of grape cells shrinkage at $40{ }^{\circ} \mathrm{C}$, as a function of time 


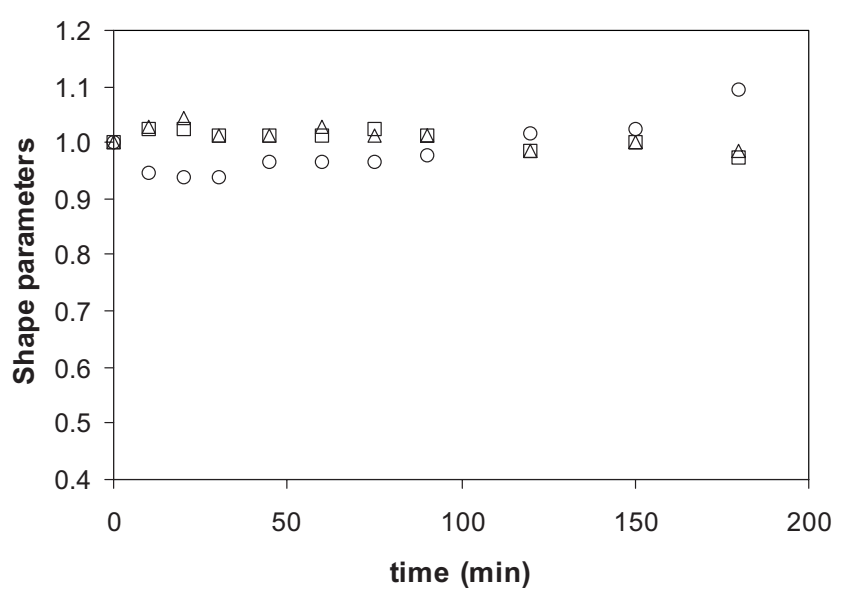

Fig. 4. Experimental shape cellular parameters, at $40{ }^{\circ} \mathrm{C}$, as a function of time. (O) Elongation, $(\triangle)$ roundness and $(\square)$ compactness.

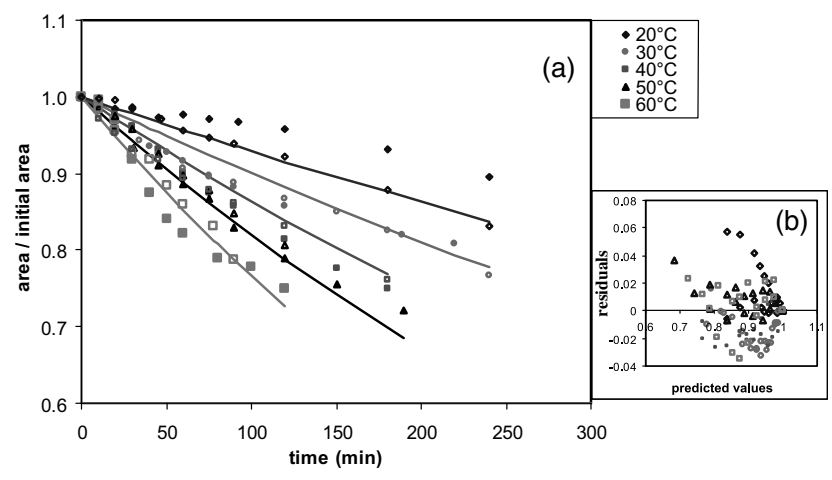

Fig. 5. (a) Experimental cellular area as a function of time and temperature. Continuous lines represent model predicted values (empty icons are replicates). (b) Model residuals as a function of predicted values.

temperature from 20 to $60^{\circ} \mathrm{C}$ increased the rate constant for area change by $350 \%$. Other cellular parameters directly related to dimension have a similar behaviour: their magnitude also decreases with drying time and higher temperatures accelerate their rate of change. Although expected, the phenomenon of 'case hardening' was not observed during the experiments drying period. Otherwise, if the formation of a crust had occurred, for the higher temperatures (higher drying rates), cellular dimensions would be kept and shrinkage would decrease. The effect of temperature on rate constant was well described by the Arrhenius model (Eq. (6)). When plotting $\ln k$ versus the reciprocal of absolute temperature, $1 / T$, a satisfactory fit to a straight line was obtained, meaning that this is a valid mathematical model to represent the temperature effect on the kinetics of cellular dimensional parameters change along drying. Cellular shrinkage depends on water removal, and the Arrhenius model is commonly used in convective drying
Table 1

Rate of change at $40{ }^{\circ} \mathrm{C}$ and activation energy, for each cellular parameter related to dimensions (kinetic parameters were obtained by a one-step non-linear regression of all data)

\begin{tabular}{lll}
\hline Cellular parameters & $k_{40}{ }^{\circ} \mathrm{C} \times 10^{-3}\left(\mathrm{~min}^{-1}\right)$ & $E_{\mathrm{a}}(\mathrm{kJ} / \mathrm{mol})$ \\
\hline Area & $1.46 \pm 0.05$ & $3.1 \pm 0.3$ \\
Perimeter & $0.89 \pm 0.05$ & $3.1 \pm 0.4$ \\
Major axis & $0.88 \pm 0.05$ & $2.9 \pm 0.3$ \\
Minor axis & $0.95 \pm 0.05$ & $3.6 \pm 0.7$ \\
FD & $0.91 \pm 0.04$ & $3.3 \pm 0.3$ \\
\hline
\end{tabular}

of intact fruits, and an analogy may be done. Kinetic cellular parameters for area, perimeter, major axis length, minor axis length and FD, are compiled in Table 1 , together with corresponding standard errors. The magnitude of the values obtained is $10^{-3} \mathrm{~min}^{-1}$ and $3 \mathrm{~kJ} /$ mol for the rate of change at $40{ }^{\circ} \mathrm{C}$ and activation energy, respectively. This is about an order of magnitude lower than the activation energy for water diffusivity during drying intact fruits (Gekas, 1992), meaning that cellular shrinkage (dimension parameters) has a lower dependence on temperature than water diffusivity in drying.

Cellular parameters directly related to shape did not show any clear trend with drying time. Bolin and Huxsoll (1987) reported that the roundness index (inverse of roundness) for cells of apple rings increased with drying, however for grape quarter cells this was not observed. Compactness and roundness remained practically unchanged. Since cellular parameters related to shape did not seem to present any tendency with temperature, a two-way analysis of variance was performed. Data were unbalanced, because experiments at different temperatures had unequally spaced observations. Although general conclusions about the effect of temperature on elongation, roundness or compactness changes along drying time could not be made, some particular remarks were derived. The lowest observed value for roundness was obtained at the higher temperature $\left(60{ }^{\circ} \mathrm{C}\right)$. No significant differences were found between the other values. Regarding the cellular compactness, the lowest values were obtained at $50{ }^{\circ} \mathrm{C}$.

Cellular elongation embraced a wider range of values when compared to roundness or compactness. This may be due to a higher sensitivity of the mathematical expression for elongation, to cell changes during drying. Elongation seemed to present a smooth tendency to increase with drying time (Fig. 6). Wang and Brennan (1995) had observed the elongation of cellular walls by microscopy during potato drying experiments. However, for these experiments with grape quarters the table of single factor ANOVA showed no significant differences. Particularly for the cellular elongation and after removing outliers, a simple linear fit at individual temperatures, was attempted. The rates of change were 


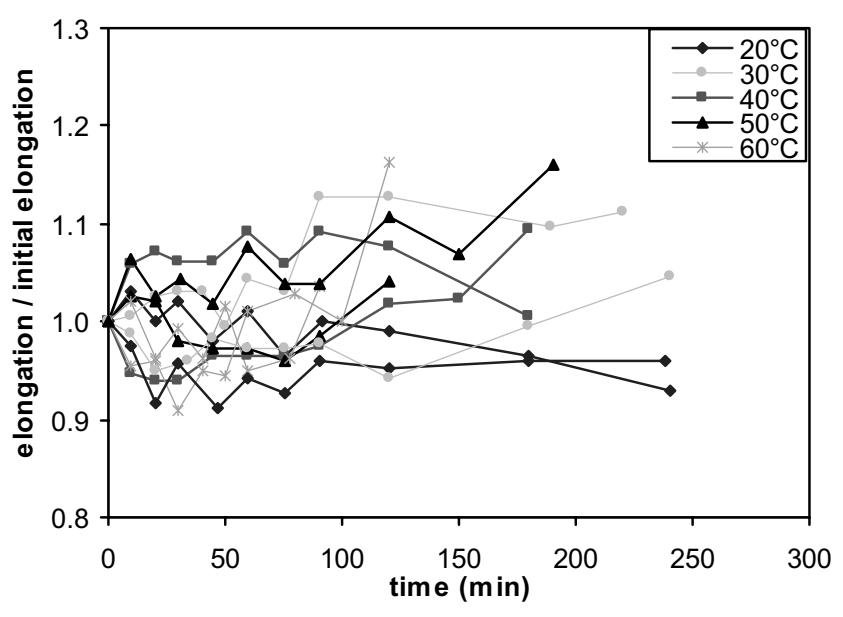

Fig. 6. Experimental cellular elongation as a function of time and temperature.

compared by single factor analysis of variance. However, the result was consistent with the previous one.

\section{Conclusions}

Stereo-microscopy has proved to be a useful noninvasive tool in studying drying at microscopic level. This technique allows monitoring the same cells from a quarter of fruit tissue during the first stage of the drying process. Cellular shape and dimensions were quantified, thanks to powerful techniques of image analysis. It was observed that the cells dimensions suffered modifications during first stage of drying, but their shape remained unchanged. A kinetic approach was successfully applied to model these microstructural changes. Area, perimeter, major and minor axis length and Feret diameter presented a smooth exponential decrease with drying time and data were well described by a first-order model. Within the studied range, temperature increased the rate of cellular shrinkage in grape quarters and this effect followed an Arrhenius type behaviour. Under the drying conditions used, it was not possible to observe any consistent trend of cellular elongation, roundness or compactness with time and no generalisation on the effect of temperature on these parameters could thus be made. Results of this research were obtained for cells from tissue of grape quarters during first stage of drying, therefore conclusions may have to be carefully extrapolated for the case of drying of intact grape berries, as occurs in raisin production.

\section{Acknowledgements}

Part of this research was supported by the RED ALFA: "Food Quality in Food Engineering" (ref: 5-
0130-9) and the CYTED XI.13: "Relaciones Estructura-Propriedad en la Deshidratacion y Almacenaje de Alimentos Dehidratados" projects. The author Inês N. Ramos would like to acknowledge PRAXIS XXI PhD grant no. $18543 / 98$ to Fundação para a Ciência e a Tecnologia, Portugal. The authors would like also to acknowledge the contribution of Dr. Laura Cadoche during the initial set-up of the experiments.

\section{References}

Aguilera, J. M., \& Lillford, P. J. (1997). Microstructural and imaging analysis as related to food engineering. In P. Fito, E. OrtegaRodríguez, \& G. Barbosa-Cánovas (Eds.), Food engineering 2000 (pp. 23-38). London: Chapman \& Hall.

Aguilera, J. M., \& Stanley, D. W. (1999). Microstructural principles of food processing and engineering (2nd ed.). Gaithersburg: Aspen Publishers.

Arabshahi, A., \& Lund, D. B. (1985). Considerations in calculating kinetics parameters from experimental data. Journal of Food Process Engineering, 7, 239-251.

Bolin, H. R., \& Huxsoll, C. C. (1987). Scanning electron microscope/ image analyzer determination of dimensional postharvest changes in fruit cells. Journal of Food Science, 6(52), 1649-1650.

Brennan, J. G. (1994). Food dehydration: a dictionary and guide. Oxford: Butterworth-Heinemann.

Crafts, A. S. (1944). Cellular changes in certain fruits and vegetables during blanching and dehydration. Food Research, 9, 442-452.

Foust, A. S., Wenzel, L. A., Clump, C. W., Maus, L., \& Andersen, L. B. (1980). Principles of unit operations (2nd ed.). Singapore: John Wiley \& Sons.

Gekas, V. (1992). Transport phenomena of foods and biological material. Boca Raton: CRC Press.

Hills, B. P., \& Remigereau, B. (1997). NMR studies of changes in subcellular water compartmentation in parenchyma apple tissue during drying and freezing. International Journal of Food Science and Technology, 32, 51-61.

Jewell, G. G. (1979). Fruits and vegetables. In J. G. Vaughan (Ed.), Food microscopy (pp. 1-34). London: Academic Press.

Karathanos, V. T., Kanellopoulos, N. K., \& Belessiotis, V. G. (1996). Development of porous structure during air drying of agricultural plant products. Journal of Food Engineering, 29, 167-183.

Lund, D. B. (1983). Considerations in modelling food processes. Food Technology, 37, 92-94.

Patil, V. K., Chakrawar, V. R., Narwadkar, P. R., \& Shinde, G. S. (1995). Grape. In D. K. Salunkhe, \& S. S. Kadam (Eds.), Handbook of fruit science and technology (pp. 7-38). New York: Marcel Dekker.

Potter, N. N., \& Hotchkiss, J. H. (1998). Food dehydration and concentration. In Food science (5th ed., pp. 200-244). Maryland: Aspen Publishers.

Ratti, C., \& Mujumdar, A. S. (1996). Drying of fruits. In L. P. Somogyi, H. S. Ramaswamy, \& Y. H. Hui (Eds.), Processing fruits: science and technology (vol. 1, pp. 185-220). Lancaster: Technomic Publishing.

Reeve, R. M. A. (1943). Microscopic study of the physical changes in carrots and potatoes during dehydration. Food Research, 8, 128136.

Wang, N., \& Brennan, J. G. (1995). Changes in structure, density and porosity of potato during dehydration. Journal of Food Engineering, 24, 61-76. 